\title{
EFEITO DA SUBSTITUIÇÃO DO MILHO PELO SORGO COM ADIÇÃO DE ENZIMAS DIGESTIVAS, SOBRE A PERFORMANCE DE FRANGOS DE CORTE
}

\section{EFFECT OF SUBSTITUTION OF CORN BY SORGHUN WITH DIGESTIVES ENZIMES ADITION ON CHICKEN PERFORMANCE}

\author{
Elza de MORAIS \\ Orientador: Professor Dr. Sebastião FRANCO \\ Departamento de Zootecnia - UFPR
}

\begin{abstract}
RESUMO
Com a finalidade de verificar os efeitos exercidos pelo sorgo em rações, isocalóricas e isoprotéicas, foram utilizados quatro níveis de sorgo $(0,15,30$ e $45 \%)$ em substituição ao milho, com adição de três níveis de enzimas $(0,750$ e $1.500 \mathrm{gE} / \mathrm{t}$ de ração), com 3 repetições por tratamento, em um delineamento experimental $(4 \times 3 \times 3)$ totalmente casualizado. As aves foram criadas em três fases, de 0-21; 22-42 e 42-49 dias, quando foram abatidas. Para o ganho médio de peso (GMP), aos 21 dias, a utilização de $45 \%$ de sorgo foi melhor que 30 e 15\%, não diferindo, contudo, da ração sem sorgo. Como aos 42 e 49 dias os resultado para

GMP não se mostraram consistentes com aqueles da primeira fase, acredita-se que a diferença ocorreu meramente ao acaso. O mesmo foi observado para conversão alimentar, uma vez que o nível de $45 \%$ de sorgo foi mais eficaz que $15 \%$. No entanto, as fases de 42 e 49 dias, não acompanharam a primeira fase, ou seja, não apresentaram diferenças. Ainda, o ganho médio de peso, conversão alimentar e consumo de alimentos não foram influenciados pela adição de enzimas, uma vez que não exerceram efeito sobre a digestibilidade de sorgo.
\end{abstract}

